\title{
CRISE HEGEMÔNICA E MOVIMENTOS SOCIAIS NO BRASIL: PARA UM PROJETO POLÍTICO-IDEOLÓGICO DOS MOVIMENTOS NEGROS
}

\author{
EDILVAN MORAES LUNA ${ }^{1}$; CLESSIANA OLIVEIRA LOPES ${ }^{2}$ \\ ${ }^{1}$ UFCG. Mestrado em Ciências Sociais pela UFCG. CV: http://lattes.cnpq.br/2939667681162112 \\ ${ }^{2}$ URCA. Estudante em Ciências Sociais pela URCA. CV: http://lattes.cnpq.br/7026931494760538
}

Artigo submetido em Junho/2016 e aceito em Julho/2016

\section{RESUMO}

$\mathrm{Na}$ atualidade, observa-se que muitas leituras feitas acerca dos contextos de manifestações de movimentos sociais se inserem dentro de uma perspectiva de políticas de identidade e de reconhecimento cultural em detrimento da justiça distributiva. Contudo, longe de concordamos com esta substituição, nossa hipótese é que o deslocamento substitutivo da justiça distributiva pelo reconhecimento cultural limita e enfraquece a própria ação dos movimentos sociais, já que ambos são faces de uma mesma moeda, de forma que a ausência de um compromete a existência de outro. A partir do pensamento de Gramsci, desenvolveremos uma leitura da questão racial no Brasil a partir da relação entre movimentos sociais negros, Estado e sociedade civil. Nosso objetivo é demonstrar que a concretização de uma verdadeira democracia racial passa pela estratégia dos movimentos de construírem um projeto político-ideológico contra-hegemônico, ocupando, dentro da lógica gramsciana de guerra de posição, espaços na esfera da sociedade civil.

PALAVRAS-CHAVE: Democracia racial. Hegemonia. Revolução passiva.

\section{ABSTRACT}

Currently, it is observed that many readings about the contexts of social movement manifestations fall within a perspective of identity politics and cultural recognition to the detriment of distributive justice. However, far from agreed with this replacement, our hypothesis is that the substitute displacement of distributive justice for cultural recognition limits and weakens the action of social movements, as both are two sides of the same coin, so that the absence of one compromises the existence of another. From the thought of Gramsci, we develop a reading of the racial question in Brazil from the relationship between black movements, State and civil society. Our goal is to demonstrate that the achievement of genuine racial democracy depends on the strategy of the movements to propose a political and ideological counter-hegemonic project, occupying within the Gramscian logic of war of position, spaces in the civil society sphere.

Keywords: Racial democracy. Hegemony. Passive revolution. 


\section{INTRODUÇÃO}

Em que tempo vivemos quando falamos de conflitos sociais? Pergunta inicialmente vaga, mas que serve como ponto de partida para as reflexões que desenvolveremos ao longo destas páginas. Com esta pergunta queremos apontar um debate que se instaurou entre finais do século XX e início do século XXI no qual se apresentava um novo rumo para as lutas dos movimentos contestatórios. Nesse debate, se colocava de um lado o esgotamento das lutas por justiça distributiva, pautadas principalmente pelo marxismo, pois o fim da União Soviética já se apresentava - exemplo de socialismo real - ruía, mostrando uma inevitabilidade de um modelo socialista de organização social. Veríamos emergir, assim, com grande ênfase o discurso pós-moderno e a luta pelo reconhecimento cultural.

O pensamento pós-moderno se apresentava como o pensamento que, longe de desejar se sistematizar em um grande modelo totalizador de pensamento, tais como os modelos kantianos, hegelianos e marxiano, tentava refletir um tempo de fins das metanarrativas, dos grandes relatos a orientar e pautar a história. O pós-moderno seria, portanto, o espaço do fragmentário, do emergente, do descontínuo, do fluído, do flexível e do intenso. Nas palavras daquele que seria reconhecido como um dos pais promotores da pós-modernidade, temos que

Considera-se 'pós-moderna' a incredulidade em relação aos 'metarrelatos'. É, sem dúvida, um efeito do progresso das ciências, mas este progresso, por sua vez, a supõe. Ao desuso do dispositivo metanarrativo de legitimação corresponde sobretudo a crise da filosofia metafísica e a da instituição universitária que dela dependia (LYOTARD, 1993, p. 3).

Juntamente com o pensamento pós-moderno, se intensificava as lutas contestatórias em torno de elementos culturais, ou seja, se ganhava destaque a luta por reconhecimento cultural. A luta por reconhecimento não esteve ausente ao longo do século $X X$. O que nos chama a atenção é como este tipo de luta ganha ênfase e destaque como substituto à luta por justiça distributiva aos moldes marxistas e socialistas. Nesse contexto, no meio intelectual, temos a figura de Axel Honneth, que em sua obra célebre Luta por reconhecimento: a gramática moral dos conflitos sociais mostra como grupos sociais e indivíduos se localizam na sociedade atual a partir de lutas por reconhecimento intersubjetivo. Baseado em leituras da filosofia de Hegel e na psicologia de George Mead, Honneth (2003) apresenta os conflitos da atualidade como conflitos morais e aborda que "nas sociedades modernas, as relações de estima social estão sujeitas a uma luta permanente na qual os diversos grupos procuram elevar, com os meios da força simbólica e em referência às finalidades gerais, o valor das capacidades associadas à sua forma de vida" (HONNETH, 2003, p. 207 grifo nosso).

Assim, dando uma resposta a pergunta que iniciou esta discussão, estaríamos vivendo tempos de movimento sociais, de luta por reconhecimento e de pós-modernidade. Estes três elementos teriam vindo para substituir, respectivamente, a classe revolucionária do proletariado, a justiça distributiva e a modernidade. Para termos uma ideia da vontade de se apresentar um pensamento alternativo àquele pensamento sobre justiça dominante no 
século XX - o socialismo -, o próprio Honneth (2003) se desvia de todo tipo de visão sistemática sobre a dominação, já que, em seus argumentos, os verdadeiros efeitos da exploração e da injustiça estão na experiência do desrespeito e nas expectativas sociais, psicológicas e morais de reconhecimento que atravessam os indivíduos em seu dia-a-dia. Porém esta resposta é apenas uma dentre outras e que suas consequências - consequências políticas e ideológicas, principalmente - desempenham um papel significativo na própria limitação dos movimentos sociais. Nossa hipótese, portanto, é que o deslocamento substitutivo da justiça distributiva pelo reconhecimento cultural limita e enfraquece a própria ação dos movimentos sociais, pois longe de reconhecimento ser um substituto de distribuição, eles são faces de uma mesma moeda, de forma que a ausência de um compromete a existência de outro. Nesse sentido, compartilhamos do pensamento de Nancy Fraser (2002) quando esta, em debate com Honneth, apresenta esse movimento substitutivo como um problema, o problema da substituição. Para Fraser, Justiça distributiva, reconhecimento cultural e participação política devem estar presentes na pauta dos movimentos sociais caso estes desejem realmente romper com as amarras da opressão que os posicionam em um local de subalternidade. Quando enfatizado apenas as políticas identitárias, o que se tem é uma falsa política do reconhecimento, pois se afirma o reconhecimento, mas não dá as condições socioeconômicas para que este reconhecimento se objetive em benefícios simbólicos e materiais para os grupos subalternizados. No contexto de substituição, damos razão a Fraser (2002, p.10-11, grifos do autor) quando diz:

\begin{abstract}
Uma das ameaças à justiça social na globalização é resultado de uma ironia histórica: a transição da redistribuição para o reconhecimento está a ocorrer apesar (ou por causa) da aceleração da globalização económica. Desta forma, os conflitos identitários alcançaram estatuto paradigmático exactamente no momento em que o agressivo capitalismo globalizante conduzido pelos Estados Unidos está a exacerbar radicalmente as desigualdades económicas. Como resultado, a viragem para o reconhecimento encaixou-se perfeitamente num neoliberalismo económico que deseja acima de tudo reprimir a memória do igualitarismo socialista. Neste contexto, as lutas pelo reconhecimento estão a contribuir menos para suplementar, tornar mais complexas e enriquecer as lutas pela redistribuição do que para as marginalizar, eclipsar e substituir. Chamo a isto o problema da substituição.
\end{abstract}

Exemplificaremos isso a partir de uma reflexão teórica sobre a ação dos movimentos negros contra a discriminação e o racismo no Brasil. Não analisaremos discursos em particular, mas estabeleceremos os limites e possibilidades deste movimento caso suas ações se pautem em apenas um dos lados dos paradigmas aqui expostos (justiça distributiva ou reconhecimento cultural).

Os limites e possibilidades dos movimentos negros no combate ao racismo e discriminação devem ser entendidos a partir de sua relação com o Estado e, principalmente, com a sociedade civil na qual estes movimentos atuam. Os movimentos sociais são agentes inseridos em um espaço social amplo, que comportam outros agentes com interesses opostos aqueles dos movimentos. Os movimentos negros ao longo do século $\mathrm{XX}$, por exemplo Frente Negra Brasileira (FNB) e o Movimento Negro Unificado (MNU), desde o pós- 
abolição vem falando sozinhos para as esferas públicas. O protesto dos movimentos sofre resistência do restante da sociedade civil, que não veem no racismo um problema social. Em outros termos, a classificação da seleção brasileira na Copa do Mundo mobiliza mais a atenção de "instâncias privadas da hegemonia" (escolas, mídias, igrejas, famílias, etc.) do que os inúmeros casos de racismo, discriminação e descasos com a população negra. O mito da democracia racial ainda é forte como discurso fundador tanto do Brasil como nação como também de caracterização do "povo brasileiro". Apenas a denúncia deste mito não é bastante para destruí-lo. É preciso compreender a dinâmica socioeconômica da sociedade brasileira para assim entender a funcionalidade do racismo no interior do território. Para entendermos a dinâmica entre sociedade civil e Estado, partiremos da contribuição do pensador italiano marxista Antonio Gramsci. Entendido esta relação, seremos capazes de compreender porque os movimentos negros não podem se limitar apenas a luta por reconhecimento, sendo essencial aderir a esta a luta pela justiça distributiva.

\section{ESTADO E SOCIEDADE CIVIL EM ANTONIO GRAMSCI}

Entre críticos e defensores do marxismo, não há aquele que não tenha despendido tempo para entender, nem que superficialmente, Antonio Gramsci. Desde aqueles que veem no marxista italiano um reformador até aqueles que o percebem como um dos mais fervorosos revolucionários, todos reconhecem a importância de Gramsci para a atualidade. Vale destacar a relevância do filósofo para os estudos culturais na pena de Stuart Hall, que trabalhando com o conceito de hegemonia, entende o racismo como ideologia de uma classe dirigente que busca construir o consenso da superioridade de uma raça sobre outras (HALL, 2003) ${ }^{1}$.

As condições de trabalho de Gramsci foram adversas. Suas obras mais importantes são seus Cadernos do Cárcere, textos de prisão na qual, devido às condições que imperavam na prisão (censura policial sobre o que escrevia, falta de materiais para conferir citações e desenvolver estudos, condições físicas e de saúde que o atormentavam), predominam uma escrita descontínua, fragmentada, complexa e que abrange vários temas considerados, para o autor, de fundamental importância para se entender o processo revolucionário em direção ao socialismo. É claro que quando escrevia, Gramsci olhava para o seu tempo e local presente (a Primeira Guerra Mundial, a Revolução Russa, os levantes operários na Europa, a formação de grandes partidos políticos, a consolidação de regimes totalitários, tal como o fascismo na Itália, a depressão econômica de 1929, a afirmação dos Estados Unidos como

\footnotetext{
${ }^{1}$ Geralmente dirige-se ao marxismo uma crítica referente ao seu suposto economicismo, ênfase sobre as estruturas mais que sobre a superestrutura. Não descartando correntes economicistas no seio do marxismo, acreditamos que a acusação de descaso desta corrente de pensamento sobre questões culturais é infundada. Entre as críticas que a corrente de pensamento na qual Hall faz parte - Estudos culturais - dirige ao marxismo, há também o reconhecimento de pontos relevantes a se pensar a cultura. Assim, Johnson (1999, p. 13) observa contribuições do marxismo para os estudos culturais "A primeira é que os processos culturais estão intimamente vinculados com as relações sociais, especialmente com as relações e as formações de classe, com as divisões sexuais, com a estruturação racial das relações sociais e com as opressões de idade. A segunda é que cultura envolve poder, contribuindo para produzir assimetrias nas capacidades dos indivíduos e dos grupos sociais para definir e satisfazer suas necessidades. E a terceira, que se deduz das outras duas, é que a cultura não é um campo autônomo nem externamente determinado, mas um local de diferenças e de lutas sociais".
}

Dialektiké, v. 1, 2016. p. 36-51 
potência hegemônica mundial). Assim, toda leitura de Gramsci no intuito de iluminar o nosso presente incorre no risco de anacronismo. Contudo,

precisamos ler Gramsci não apenas situando-o em seu tempo, mas situando-o hoje, na história que estamos vivendo e que ele não viveu: retomar seu discurso criador, não no vazio nebuloso de desejos e sonhos, mas a partir da concretude real e histórica. O seu legado não nos ajuda apenas a pensar o passado, mas põe no presente a perspectiva da revolução, que é hoje a luta pela democracia e pelo socialismo (SIMIONATTO, 1995, p. 254-255).

O instrumental teórico deixado pelo autor nos permite pensar as condições brasileiras em temas específicos, mesmo que isso nos custe, em parte, simplificarmos

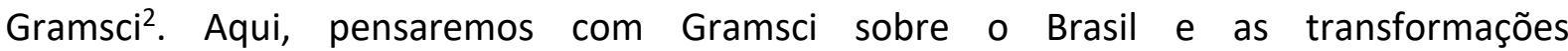
socioeconômicas ocorridas que expliquem a subalternidade da população negra até os dias de hoje.

A pergunta de partida para Gramsci foi: por que a revolução falhou na Itália e em outros países da Europa, quando na Rússia, ela foi possível? Essa pergunta o leva a analisar a realidade específica da Europa, da Itália e da Rússia. O que sua análise mostrou é que a composição societária de cada região corroboraria ou refutaria a possibilidade revolucionária. Em sociedades Orientais (oriental e ocidental não são categorias geográficas em Gramsci, mas categorias políticas e socioeconômicas), estas seriam marcadas por um Estado que seria tudo, enquanto a sociedade civil pouco significaria. Já em sociedades Ocidentais, a sociedade civil seria mais desenvolvida, representando até mesmo "fortalezas", "trincheiras", "casamatas" a protegerem o Estado. Como observa o próprio autor:

no Oriente, o Estado era tudo, a sociedade civil era primitiva e gelatinosa: no ocidente, havia entre o Estado e a sociedade civil uma relação apropriada e, ao oscilar o Estado, podia-se imediatamente reconhecer uma robusta estrutura da sociedade civil. 0 Estado era apenas uma trincheira avançada, por trás da qual se situava uma robusta cadeia de fortalezas e casamatas (GRAMSCl, 1977, p. 866 tradução nossa)

O que Gramsci quer dizer com isso é que, separando a nível analítico sociedade civil de Estado (sociedade política, Estado em sua dimensão restrita de aparelho burocrático e coercitivo), um país em que a força de uma classe está tanto no aparelho burocrático e

\footnotetext{
2 “Gramsci foi rapidamente difundido no Brasil, mas acabou por funcionar como 'meio' para o estabelecimento de um descompromissado flerte com o marxismo e para emprestar autoridade às ideias mais estranhas, regra geral arquitetadas a partir de uma operação preocupada em manipular as categorias gramscianas como se tratasse da peça de um puzzle cuja resolução pouco interessava. Seu pensamento terminou assim por ser reduzido a conceitos, desvinculado de qualquer dimensão doutrinária mais abrangente e, sobretudo, separado da perspectiva de transformação socialista e da particular teoria do Estado que fazem de Gramsci um ponto de inflexão na história do marxismo e do movimento operário". (NOGUEIRA, 1988, p. 131)
}

Dialektiké, v. 1, 2016. p. 36-51 
coercitivo, via coerção, como no seio da própria sociedade civil, via consensos, não basta uma marcha direta em direção ao Estado (guerra de movimento), mas sim uma guerra de posição, na qual os revolucionários devem se mover por entre a sociedade civil organizando um consenso sobre um novo projeto societário. O que está em questão, portanto, é que

a supremacia de um grupo se manifesta de dois modos, como "domínio" e como "direção intelectual e moral". Um grupo social domina os grupos adversários, que visa a "liquidar" ou a submeter inclusive com a força armada, e dirige os grupos afins e aliados. Um grupo social pode e, aliás, deve ser dirigente já antes de conquistar o poder governamental (esta é uma das condições fundamentais inclusive para a própria conquista do poder); depois, quando exerce o poder e mesmo se o mantém fortemente nas mãos, torna-se dominante, mas deve continuar a ser também [dirigente] (GRAMSCl, 2002, p. 62-63).

Assim, se a revolução tinha fracassado ou sofria resistência na Europa, é porque esta era mais complexa do que pensava as perspectivas economicistas de certa ala do marxismo. Enquanto a perspectiva economicista esperava por uma crise econômica que viesse a ameaçar de morte o capitalismo, Gramsci considerava uma defasagem entre economia e ideologia, mostrando que mudanças ideológicas não caminham pari passu com mudanças econômicas, o que significaria que mesmo diante de um contexto de crises econômicas severas, a crença na liderança de uma classe dirigente repercutira como forte resistência ao movimento revolucionário. Não é apenas a crise que impulsiona para o novo, mas o projeto societário já existente como consenso na sociedade civil que fundamenta e fortalece a transição para uma nova organização social. Essa perspectiva reforça, portanto, a ideia de que o movimento revolucionário deve minar as forças hegemônicas do poder vigente antes mesmo de tomar o poder do Estado. Nesse sentido, a tomada do Estado seria a consequência de algo que já estava sendo gestado antes, no seio da própria sociedade civil. Como aponta Luciano Gruppi (1978, p. 67).

uma classe é hegemônica, dirigente e dominante até o momento em que através de uma classe sua ação política, ideológica, cultural - consegue manter articulado um grupo de forças heterogêneas e impedir que o contraste existente entre tais forças exploda, provocando assim uma crise na ideologia dominante, que leve à recusa de tal ideologia, fato que irá coincidir com a crise política das forças no poder.

O conceito de hegemonia deriva do grego eghestai e significa "conduzir", "ser guia", "ser chefe". Uma classe hegemônica é aquela que abre mão de parte de seus interesses para dirigir o todo de uma sociedade. Esta classe se apresenta como a que sua visão de mundo é a "verdadeira", a "melhor", a "única" a caminhar em direção do progresso e bem-estar de todos. Por isso ela é dirigente e se faz valer como dirigente através de uma série de instituições como aquelas que Althusser intitulou como aparelhos ideológicos de Estado (AIE), tais como 
um certo numero de realidades que se apresentam ao observador imediato sob a forma de instituições distintas e especializadas [...] O AIE religioso (o sistema das diferentes Igrejas), O AIE escolar (o sistema das diferentes escolas públicas e particulares), O AIE familiar, O AIE jurídico, O AIE político (o sistema político de que fazem parte os diferentes partidos), O AIE sindical, O AIE da informação (imprensa, rádio-televisão, etc.) (ALTHUSSER, 1970, p. 43-44).

Gramsci mostra para os revolucionários que uma transformação socioeconômica e política profunda demandarão da classe trabalhadora, classe revolucionária, a construção de uma hegemonia, mas não mais aquela hegemonia burguesa - a direção de uma classe (fração de classe burguesa) em nome de seus interesses -, mas uma hegemonia cujo intuito é geralmente romper com as condições objetivas e subjetivas da própria dominação de classe.

Se a dinâmica social de uma nação exige mudanças pelas classes dirigentes, quando esta classe dirigente é a própria burguesia, as transformações socioeconômicas se dão dentro dos moldes de uma revolução passiva. Quando, se referindo à Itália, emerge o fascismo

[...] ter-se-ia uma revolução passiva no fato de que, por intermédio da intervenção legislativa do Estado e através da organização corporativa, teriam sido introduzidas na estrutura econômica do país modificações mais ou menos profundas a fim de acentuar o elemento "plano de produção", isto é, teria sido acentuada a socialização e a cooperação da produção, sem com isso tocar (ou limitando-se apenas a regular e controlar) a apropriação individual e grupal do lucro. No quadro concreto das relações sociais italianas, esta pode ter sido a única solução para desenvolver as forças produtivas da indústria sob a direção das classes dirigentes tradicionais, em concorrência com as mais avançadas formações industriais de países que monopolizam as matérias-primas e acumularam gigantescos capitais. (GRAMSCl, 2006, p. 299).

Uma revolução passiva, portanto, pressupõem mudanças socioeconômicas significativas sem se tocar as estruturas hierárquicas de poder, ou seja, muda-se profundamente para conservar a mesma estrutura de poder entre as classes. Esta revolução passiva, por sua vez, tem a anuência do próprio Estado, pois, este, longe de ser o famoso leviatã a pairar sobre a sociedade, organizando-a e buscando a felicidade comum para todo, se revela como um órgão de manutenção da relação de classe. Ao se apresentar como não servindo a nenhuma classe, ou melhor, arbitrando entre classes, o Estado camufla a relação de classes além de assegurar a ordem sociometabólica entre capital e trabalho, e tudo isto porque 
a crescente intervenção estatal por meio das políticas sociais é em si mesma a manifestação da natureza contraditória do capitalismo, que tem na necessidade do Estado de atuar como forma de atenuação dos efeitos destrutivos da ordem capitalista sobre os fatores de produção, mas cuja intervenção torna-se, por sua vez, elemento de potencialização e agudização da contradição básica deste modo de produção entre a socialização das forças produtivas e a apropriação da riqueza social (FLEURY, 1994, p. 11).

Feitas essas considerações sobre o pensamento de Gramsci, agora o repetiremos tendo vista a realidade brasileira e, pondo como agente a revolucionar sua condição de subalternidade a população negra. Porém, antes, apresentemos um pouco a questão racial no Brasil.

\section{A QUESTÃO RACIAL NO BRASIL}

São, aproximadamente, quase 130 anos de abolição da escravidão no Brasil. Ao longo desses anos se construiu um "mito da democracia racial", discursos e práticas que enfatizavam e ainda enfatiza um provável caráter mestiço do povo brasileiro, caráter este que dá unidade a um país heterogêneo em culturas, em regiões e em povos. $O$ discurso da democracia racial é fruto de uma série de fatores históricos, presentes mesmo antes da abolição, que conjugados deram, a partir da década de 1930, um cenário para o discurso fraterno das "raças", e que teve como ilustre porta-voz Gilberto Freyre.

Porém, pouco antes de Freyre publicar a obra que o tornaria um clássico dos intérpretes do Brasil, vale lembrar que a ideologia dominante no que concernia a leitura do problema racial brasileiro eram, centralmente, duas. De um lado o "Brasil sem futuro" dos estrangeiros que aqui aportavam como Louis Agassiz e o conde de Gobineau, duas figuras representantes da defesa das teorias da degenerescência racial (a mestiçagem provocava a degenerescência das raças, pois os males das raças se concentravam no fruto do cruzamento). Do outro lado, o "Brasil de futuro branco", leitura que, sem deixar de se inspirar nas teorias racialistas dominantes na Europa desde o século XVIII (cf. POLIAKOV, 1974), defendia um branqueamento social via mestiçagem e incentivo a imigração. Esta última era a leitura da elite intelectual e política brasileira que, embora pudessem compartilhar de sangue europeu ou ser até mesmo um mestiço, não poderiam deixar de se opor ao fato de ser a elite de uma sociedade "condenada" (CANDIDO, 1978). No meio intelectual, figuras como Nina Rodrigues e Silvio Romero além de instituições como os Museus (Museu Nacional, Museu Paulista, Museu Nacional Paraense) Institutos Históricos e Geográficos, as Faculdades de direitos (de Recife e de São Paulo) e as Faculdades de medicinas (Faculdade de medicina da Bahia), por exemplo, desempenharam papeis importantes na promoção de um racismo científico no país, contribuindo, principalmente por meio da divulgação de um darwinismo social ou evolucionismo social, com políticas eugênicas. Já no início do século XX, no meio político e intelectual, figuras como Oliveira Vianna, Miguel Couto, Francisco Campos, Plínio Salgado, Gustavo Barroso, Belisário Penna e Fernando de Azevedo, dentre outros, contribuíram como podiam na promoção e construção de um país "sadio" e "limpo" eugenicamente. Como afirma Jerry Dávila (2006), o 
branqueamento seria a "metáfora social" para o progresso do Brasil, pois o passado foi negro (atrasado) e o presente de branqueamento seria o caminhar para um futuro branco (civilizado).

Próximo de meados do século XX, mudanças na conjuntura política e econômica nacional e internacional favoreceram condições para a construção discursiva da ideia de democracia racial, embora esta aparecesse como propaganda dominante mesmo em face às desigualdades raciais crescentes. Quiçá os interesses das elites em fortalecer, ou melhor, construir um Estado-Nação nos moldes de uma perfeita "comunidade imaginada" (ANDERSON, 2008) se sobrepujaram, agindo contra qualquer manifestação discursiva explícita que ameaçasse a unidade desta comunidade, como, por exemplo, a ideia de um país racista. Contudo, o fato de se falar da mestiçagem, dando ao mestiço (mulato) um caráter positivo ao invés do caráter negativo das teorias racialistas do século XIX, não significou que isso tenha feito, de fato, do país uma "democracia racial". Ao contrário, ao se falar muito desta, escondia-se as manifestações de racismo, preconceito e discriminação existentes na sociedade. A especificidade do racismo brasileiro estaria, portanto, na disparidade entre o que se diz e o que se faz, ou seja, um racismo que é sui generis, que não se reconhece como tal, que se dissimula por trás de véus de etiqueta (FERNANDES, 1978) e que se dizendo não racista, perpetra sua "violência simbólica" sobre a população negra.

A visão do Brasil sem preconceito e discriminação, exemplo a ser seguido por países como EUA e África do Sul, era bastante forte a ponto de chamar a atenção da UNESCO que, em 1950, desenvolveu um projeto de estudo cujo pano de fundo foi às relações raciais no Brasil, este entendido como um verdadeiro laboratório racial que soube lidar com possíveis problemas raciais advindos da abolição. Mas o projeto, que constou com a presença de intelectuais como Florestan Fernandes, Roger Bastide, Luiz de Aguiar Costa Pinto, Oracy Nogueira, Thales de Azevedo, Charles Wagley, René Ribeiro e Marvin Harris, chegaram a conclusões diferentes do esperado, já que autores como Florestan Fernandes, que juntamente com Roger Bastides estudou os negros em São Paulo, apontaram a existência, mesmo após abolição, de um racismo suave, em volta de véus de etiquetas, herança de um passado escravista que ainda se perpetua na sociedade de classes. Os estudos posteriores de Fernandes e de seus alunos, destacadamente, Octavio lanni e Fernando Henrique Cardoso, se concentraram em mostrar que a integração do negro na sociedade de classes se deu de maneira subordinada e de reciprocidades assimétricas (IANNI, 1987), o que significava que havia integração social do negro, mas desde que este soubesse o "seu lugar", lugar herdado dos tempos escravistas.

Ao longo do século XX, movimentos sociais negros e intelectuais intensificaram as denúncias contra um "mito da democracia racial", mito que age mais como uma função ideológica de dissimulador de desigualdades raciais do que a constatação factual de direitos, de oportunidades, de liberdade, enfim, da constatação da expansão da cidadania àquela população cujo passado de mais de três séculos foi de exploração e inferiorização de si e de suas culturas. Porém, por ser um mito, isso não o faz precisamente ser uma mentira. Dentro de uma estrutura de relações de dominação, o mito ganha uma dimensão prática e funcional, quase com a mesma função que teria para uma cultura primitiva nos moldes que pensou Malinowski, ou seja, o mito: 
[...] expressa, reforça e codifica a crença; ele salvaguarda e impõe moralidade; ele faz valer a eficiência do ritual e contem regras práticas que guiam o homem. O Mito, portanto, é um ingrediente vital da civilização humana; ele não é um conto de fadas, mas uma força ativa arduamente trabalhada; não é uma explicação intelectual ou uma imaginação artística, mas uma carta programática da fé primitiva e da sabedoria moral (MALINOWSKI, 1948, p. 79, tradução nossa) $)^{3}$.

Da explicação de Malinowski, podemos substituir a ideia do mito em uma comunidade primitiva para a comunidade brasileira do século $X X$, preservando suas especificações funcionais. O mito da democracia racial foi e ainda é uma regra prática de orientação de ações e que, por garantir privilégios, é útil e válido em uma ordem capitalista competitiva. Peggy McIntosh (1988), por exemplo, lista 62 privilégios centrados no benefício de ser branco, o que corrobora a ideia da divisão entre "raças" como sendo algo racional, com uma lógica própria de manutenção e garantia de benefícios para a camada branca da população em detrimento da população negra, pois como lembra a autora, ser branco é carregar uma mochila com "provisões especiais, mapas, passaportes, livros de códigos, vistos, roupas, ferramentas e cheques em branco" (Idem, 1988, p. 1) ${ }^{4}$. Deste modo, por mais que se apontem os malefícios do racismo e da ideia de "raça" para uma sociedade democrática, é preciso entender que dentro das relações de dominação e poder existentes na sociedade brasileira entre identidades étnico-raciais o racismo persiste porque é funcional e se legitima na própria ordem econômica capitalista, proporcionando lucros para uns a custa do prejuízo de outros. Dando a palavra a lanni $(2004$, p. 23) pensemos que:

A raça, a racialização e o racismo são produzidos na dinâmica das relações sociais, compreendendo as suas implicações políticas, econômicas, culturais. É a dialética das relações sociais que promove a metamorfose da etnia em raça. A "raça" não é uma condição biológica como a etnia, mas uma condição social, psicossocial e cultural, criada, reiterada e desenvolvida na trama das relações sociais, envolvendo jogos de forças sociais e progressos de dominação e apropriação. Racionalizar uns e outros, pela classificação e hierarquização, revela-se inclusive uma técnica política, garantindo a articulação sistêmica em que se fundam as estruturas de poder. Racializar ou estigmatizar o "outro" e os "outros" é também politizar as relações cotidianas, recorrentes, em locais de trabalho, estudo e entretenimento; bloqueando relações, possibilidades de participação, inibindo aspirações, mutilando práxis humana, acentuando a alienação de uns e outros, indivíduos e coletividades. Sob todos os aspectos, a "raça" é

\footnotetext{
3 "[...] Myth fulfills in primitive culture an indispensable function: it expresses, enhances, and codifies belief; it safeguards and enforces morality; it vouches for the efficiency of ritual and contains practical rules for the guidance of man. Myth is thus a vital ingredient of human civilization; it is not an idle tale, but a hard-worked active force; it is not an intellectual explanation or an artistic imagery, but a pragmatic charter of primitive faith and moral wisdom".

4 "I have come to see white privilege as an invisible package of unearned assets that I can count on cashing in each day, but about which I was 'meant' to remain oblivious. White privilege is like an invisible weightless knapsack of special provisions, assurances, tools, maps, guides, codebooks, passports, visas, clothes, compass, emergency gear, and blank checks" (MCINTOSH, 1988, p. 1).
}

Dialektiké, v. 1, 2016. p. 36-51 
sempre "racialização", trama de relações no contraponto e nas tensões "identidade", "alteridade", "diversidade", compreendendo integração e fragmentação, hierarquização e alienação.

Como reação dos movimentos negros contra o mito da democracia racial, o Brasil viu nascerem movimentos sociais como a Frente Negra Brasileira (1931) e o Movimento Negro Unificado (1978). Muitas vezes acusados de querer implantar uma cisão racial aonde não havia (ironicamente, o Brasil foi o último país a abolir legalmente a escravidão e o primeiro a proclamar a democracia racial), estes movimentos interpretavam e agiam como podia na melhoria da condição do negro. A Frente Negra Brasileira (FNB), por exemplo, via na educação uma ferramenta importante para que o negro tomasse consciência de sua condição e lutasse por seus direitos. "Acreditava-se que os negros, na medida em que progredissem no campo educacional, seriam respeitados, reconhecidos e valorizados pela sociedade mais abrangente. A educação teria o poder de anular o preconceito racial e, em ultima instância, de erradicá-lo" (DOMINGUES, 2008, p.522-523). Enquanto a FNB era marcada pelo seu aspecto assimilacionista do povo negro à identidade nacional, o Movimento Negro Unificado (MNU) é caracterizado pelo combate ao racismo a partir da estratégia de inclusão diferencialista. Se aproximando da cultura africana como sinal de identidade, o MNU tinha como princípio ideológico o internacionalismo e uma orientação marxista, identificando na herança escravista e no sistema capitalista as causas da marginalização do negro. Enquanto para a FNB a solução para o racismo era a via educacional, para o MNU era a via política ("negro no poder!"). Ainda sobre a mobilização negra contra a discriminação e o preconceito, podemos contar também os inúmeros jornais e outras instituições que compuseram a história dos movimentos negros no século XX e XXI.

Já, olhando para a política brasileira, observamos que o projeto político-ideológico varguista a partir da década de 1930 consolidou um consenso de unidade Nacional ao Brasil. Até 1888 a escravidão dividia o país de diferentes maneiras (livres/cativos, brancos/negros, abolicionistas/escravistas, monarquistas/republicanos, liberais/conservadores), sendo difícil falar em um único povo brasileiro. Após a abolição, a preocupação racial persistia na preocupação da elite branca em viver em um país negro. Políticas eugênicas e de branqueamento estavam no centro das atenções até meados da década de 1930. Contudo, com Vargas, a partir da década de 1930, não só teremos uma mudança no discurso público oficial para a defesa da mestiçagem (Gilberto Freyre publica Casa-Grande \& Senzala em 1933) como seu projeto econômico desenvolvimentista atendeu as necessidades de empego da população pobre dos centros urbanos que, em grande parte, de negros, viam em Vargas um "pai dos pobres". Assim, o negro seria absorvido pela sociedade de classes, subordinadamente, mas contemplando em um projeto político os grupos mais pobres e marginalizados da população. A política varguista cria uma hegemonia na qual coopta diferentes grupos e classes da população em nome de um projeto de Nação brasileira. 0 Estado, portanto, seria o promotor do discurso do Brasil Nação, exercendo, assim, o papel que the coube na revolução passiva que consolidava as estruturas de classes sociais no país, o papel de dirigente econômico, político e ideológico. Como escreveria Gramsci (2002, p. 328-9):

Este fato é da máxima importância para o conceito de 'revolução passiva': ou seja, que um grupo social não seja o dirigente de outro grupo social, mas que o Estado, ainda que limitado como potência, seja o 'dirigente' do grupo 
que deveria ser dirigente e possa colocar à disposição deste um exército e uma força político-diplomática.

Desta forma, no contexto aqui exposto, a integração do negro na sociedade de classes após a abolição se deu de forma assimétrica e subordinada as interesses das elites, sendo a democracia racial brasileira um "pacto econômico e político que uniu a massa negra urbana (formada principalmente por trabalhadores) e os intelectuais negros ao establishment (elites políticas, intelectuais e econômicas) do Estado desenvolvimentista" (GUIMARÃES, 2002, p. 11), porém sem fazer desaparecer na mentalidade de alguns intelectuais influentes do governo Vargas (Oliveira Viana, Miguel Couto, Francisco Campos, Plínio Salgado, Gustavo Barroso, Belisário Penna, Fernando de Azevedo) teses racialistas. Prática e discurso tomam caminhos diferentes. Grita-se para todos ouvirem um Brasil "cadinho de raças", Brasil "caldo cultural", Brasil da mulata que representa o "encontro de raças; uma pororoca cultural" (CORRÊA, 1996, p. 47), mas as práticas sociais conservam a mesma visão sobre o negro que se tinha no século XIX e início do século XX.

\section{ESTADO, HEGEMONIA E A LUTA DO MOVIMENTO NEGRO}

As estratégias de lutas de movimentos subalternos tem, como prioridade, conhecer as especificidades nacionais e regionais de seu campo de atuação. O movimento negro, por exemplo, se depara com uma relação socioeconômica e histórica peculiar, na qual, diferente de outros países (Estados Unidos da América e África do Sul) onde imperou um sistema de segregação e discriminação racial forte e aberto, no Brasil prevaleceu à dissimulação do racismo, ou seja, um investimento prático-discursivo significativo para se construir a imagem de um país democrático racialmente (ironicamente fomos o último país a abolir a escravidão e o primeiro a proclamar democracia racial), negando enfaticamente a presença de racismo em terras tupiniquins. Quiçá manifestações de preconceito seriam ações individuais de sujeitos pouco esclarecidos. Já discriminação racial, como seria esta possível em uma terra onde todos trazem no sangue uma mistura de branco, negro e índio (FREYRE, 2003).

Contra a hegemonia de um discurso que prega a democracia racial, será fundamental a construção de um discurso contra-hegemônico, capaz não só de denunciar o racismo velado, mas, principalmente, de construir e mobilizar um projeto capaz de fundamentar um novo consenso socioeconômico e político para a nação capaz de fornecer as condições objetivas para uma verdadeira democracia racial. A distribuição do poder econômico e político da nação se encontram entregue a frações de classes burguesas que através de seus aparelhos coercitivos e ideológicos fundamentam um projeto de nação pautado na concorrência, na competitividade e na desigualdade, sendo estas faces de uma sociedade capitalista. Em uma sociedade onde se prevalece a desigualdade socioeconômica, a construção simbólica de determinados significados desempenha papel importante na manutenção de privilégios para indivíduos e grupos. Quando posicionados socioeconomicamente em linhas de pobrezas e precariedade do trabalho, veta-se a população negra não só recursos (tempo e dinheiro, por exemplo) para construírem a si e a sua cultura, como, e isso é o mais importante, veta-se a própria percepção de sua condição de subalternidade, pois a "tomada de consciência" não emana de uma vontade inicial do 
indivíduo, mas de condições de possibilidades históricas. Em termos gramscianos, o que chamamos a atenção é para que "[...] a 'natureza' humana não residia dentro do indivíduo, mas na unidade do homem e das forças materiais: portanto, a conquista das forças materiais é uma maneira - e a mais importante - de conquistar a personalidade (Gramsci, 2001, p. 262)". O homem é um sujeito que constrói a si historicamente e que tal construção se faz, contemporaneamente, a partir de relações de poder e lutas de classes que estabelecem padrões de denominação política, exploração econômica e subjetivações específicas (o sujeito adequado é aquele que incorpora em seu corpo e sua alma o ethos capitalista). Vale lembrar que Gramsci retoma aqui a complexidade do que significa capitalismo. A referência comum ao capitalismo como modo de produção conduziu a simplificações economicistas perigosas. O capitalismo não é só modo de produção (no sentido econômico de produzir para compra, venda, lucro), mas modo de produção social da existência, o que inclui tanto a produção econômico-material, como a própria produção de sujeitos, de corpos, de subjetividades. Nesse sentido é que Gramsci fala em uma "conquista da personalidade" que passa por uma "conquista das forças materiais", pois é a partir de como os homens se organizam para produzir sua existência objetivamente que se estabelecem os limites da subjetividade ${ }^{5}$.

Atualizando o debate a partir de Gramsci, a política de reconhecimento cultural, de construção de identidade (conquista de personalidade) tem que ser acompanhada da luta por justiça distributiva (conquista das forças materiais) caso se deseje o fim da condição de subalternidade da população negra. Na construção de uma contra-hegemonia à democracia racial, a luta por reconhecimento se soma a luta por justiça distributiva (em outros termos, poderíamos apresentar este mesmo debate na forma de um "aparente" conflito entre raça e classe).

Outra lição gramsciana é que a manutenção das estruturas de classes atravessa a sociedade civil, pois nesta se encontra muitos dos "aparelhos privados da hegemonia" do discurso da democracia racial. Em escolas, partidos, igrejas, mídia ${ }^{6}$, etc. se constrói a imagem de um país "mestiço", mas branqueado. Pensemos na pouca presença nas instâncias políticas de negros, de sua representação na mídia, na dificuldade de implantação do ensino de história e cultura afro-brasileira nas escolas, do não reconhecimento e preconceito às religiões de matriz africana, na desigualdade salarial entre brancos e negros no mercado de trabalho, dentre outros casos. Estes são todos exemplos de resistência, na própria sociedade

\footnotetext{
${ }^{5}$ Gramsci, aqui, retoma os passos de Marx (2008, p.47): “o resultado geral a que cheguei e que, uma vez obtido, serviu-me de guia para meus estudos, pode ser formulado, resumidamente, assim: na produção social da própria existência, os homens entram em relações determinadas, necessárias, independentes de sua vontade; essas relações de produção correspondem a um grau determinado de desenvolvimento de suas forças produtivas materiais. A totalidade dessas relações de produção constitui a estrutura econômica da sociedade, a base real sobre a qual se eleva uma superestrutura jurídica e política e à qual correspondem formas sociais determinadas de consciência. O modo de produção da vida material condiciona o processo de vida social, política e intelectual. Não é a consciência dos homens que determina o seu ser; a contrario, é o seu ser social que determina sua consciência [...]".

${ }^{6}$ A mídia (órgãos de formação de opinião pública) sã analisados por Gramsci pelo importante papel que eles desempenham na formação e consolidação de uma hegemonia. Nas suas palavras: "O exercício 'normal' da hegemonia, no terreno tornado clássico do regime parlamentar, caracteriza-se pela combinação da força e do consenso, que se equilibram de modo variado, sem que a força suplante em muito o consenso, mas, ao contrário, tentando fazer com que a força pareça apoiada no consenso da minoria, expresso pelos chamados órgãos da opinião pública - jornais e associações -, os quais, por isso, em certas situações, são artificialmente multiplicados" (GRAMSCI, 2000, p. 95)
}

Dialektiké, v. 1, 2016. p. 36-51 
civil (sociedade civil heterogênea), do reconhecimento de problemas que afetam a população negra. Há um preconceito, uma representação social negativa e danosa para com os negros, mas essa representação, como já dissemos, se sustenta e se justifica a partir de condições socioeconômicas objetivas. A mobilização dos movimentos na ocupação de espaços dentro de diferentes lugares da sociedade civil compõe uma verdadeira guerra de posição, que, pouco a pouco, marcha em direção ao Estado (sentido restrito), pressionandoo por políticas públicas, mas que estas, por sua vez, são limitadas pela estrutura de relações de classes, relações estas que são fundantes do próprio Estado. Os estudos de Gramsci nos apontam que o Estado não é uma figura neutra, e sim um Estado-classe, de classe capitalista, que exclui a possibilidade de igualdade econômica. Assim,

\begin{abstract}
Enquanto existir o Estado-classe não pode existir a sociedade regulada [...] nos tipos de sociedade pensados pelas diversas utopias introduz-se a igualdade econômica com base necessária da reforma projetada: nisto os utopistas não eram utopistas, mas cientistas concretos da política e críticos coerentes. [...] Mas permanece o conceito [...] de que não pode existir igualdade política completa e perfeita sem igualdade econômica [...] (GRAMSCl, 2000, p. 223-224 grifo nosso)
\end{abstract}

A luta por reconhecimento se soma a luta por igualdade econômica e esta luta, por sua vez, é a luta contra o sistema de produção da existência social capitalista ${ }^{7}$. Dentro dos limites do capitalismo, apenas a política de reconhecimento é aceitável, mas limitada, pois se concede o direito oficial (direito proclamado pelo Estado) de "existir" como identidade, mas as condições objetivas, materiais para concretizar esta existência plena e digna é negada. Negada não pelo Estado, mas por um sistema socioeconômico que existe como tal a partir da subordinação, inferiorização e exploração de parte da população.

Deste modo, concluímos que aluta antirracista, portanto é a luta anticapitalista e vice-versa e que a construção de uma contra-hegemonia é fundamental, tendo sempre em vista: 1) a união dos grupos subalternos contra sua condição subalternizada, cada qual ultrapassando suas "demandas corporativistas" (interesses imediatos específicos de cada grupo contestatório) e avançando em um projeto societário contrário aquele projeto capitalista e; 2) o trabalho e luta nas diferentes instâncias da sociedade civil, confrontando as "formas legais" de reprodução capitalista, como, por exemplo, na escola e através da educação. Formas estas que se sustentam na desigualdade socioeconômica e na hegemonia de classes dirigentes burguesas.

\title{
REFERÊNCIAS
}

\footnotetext{
${ }^{7}$ Em outro momento Gramsci se pergunta: "Pode haver reforma cultural, ou seja, elevação civil das camadas mais baixas da sociedade, sem uma anterior reforma econômica e uma modificação na posição social e no mundo econômico? É por isso que uma reforma intelectual e moral não pode deixar de estar ligada a um programa de reforma econômica; [...]" (GRAMSCI, 2000, p. 19)
}

Dialektiké, v. 1, 2016. p. 36-51 
ALTHUSSER, Louis. Ideologia e Aparelhos ideológicos de estado. Lisboa: Presença 1970.

ANDERSON, Benedict. Comunidades imaginadas: reflexões sobre a origem e a difusão do nacionalismo. São Paulo: Companhia das Letras, 2008.

CANDIDO, Antonio. Silvio Romero: teoria, crítica e história literária. São Paulo: Edusp, 1978.

DÁVILA, Jerry. Diploma de brancura: política social e racial no Brasil 1917-1945. São Paulo: Editora da UNESP, 2006.

DOMINGUES, Petrônio. Um “templo de luz": Frente Negra Brasileira (1931-1937) e a questão da educação. Isso. Bras. Educ., Dez 2008, vol.13, no.39.

FERNANDES, Florestan. A integração do negro na sociedade de classes. 3 a. Ed. São Paulo: Ática, 1978, v. 1.

FLEURY, Sonia. Estado sem cidadão: seguridade social na America Latina. Rio de Janeiro: Fiocruz, 1994.

FRASER, Nancy. A Justiça Social na Globalização: redistribuição, reconhecimento e participação. Trad. Teresa Tavares. In: Revista Crítica de Ciências Sociais, n. 63, out. 2002.

FREYRE, Gilberto. Casa Grande \& Senzala: formação da família brasileira sob o regime da economia patriarcal. 48ª ed. São Paulo: Globo, 2003.

GRAMSCl, Antonio. Cadernos do cárcere - Os Intelectuais. O Princípio Educativo. Jornalismo. Rio de Janeiro: Civilização Brasileira, 2000. v. 2.

. Cadernos do Cárcere. 4 ed. Rio de Janeiro: Civilização Brasileira, 2006. V. 1.

Quaderni del carcere. Edizione critica Dell'Istituto Gramsci di Roma. Torino, 1977.

. Cadernos do Cárcere. Rio de Janeiro: civilização Brasileira, 2000, V. 3.

. Cadernos do cárcere. Rio de Janeiro: Civilização Brasileira, 2002, V. 5.

GRUPPI, Luciano. O conceito de hegemonia em Gramsci. Rio de Janeiro: Graal, 1978.

GUIMARÃES, Antonio Sérgio Alfredo. Classes, raças e democracia. São Paulo: Editora 34, 2002.

HALL, Stuart. Da Diáspora: identidades e mediações culturais. Belo Horizonte: UFMG, 2003.

HONNETH, A. Luta pelo reconhecimento: a gramática moral dos conflitos sociais. Rio de Janeiro: Editora 34, 2003. 
IANNI, Octavio. Dialética das relações raciais. Estud. Av., São Paulo , v. 18, n. 50, p. 21-30 Abr. 2004 . Disponível em <51TTP://www.scielo.br/scielo.php?script=sci_arttext\&pid=S0103$40142004000100003 \&$ Ing=en\&nrm=iso>. Acesso em 12 Mar. 2016.

IANNI, Octavio. Raças e classes socais no Brasil. 3ạ edição. São Paulo: editora brasiliense, 1987.

JOHNSON, Richard. O que é, afinal, estudos culturais? In: SILVA, Tomaz T. da, (org.). O que é, afinal, estudos culturais. Belo Horizonte: Autêntica, 1999.

LYOTARD, Jean-François. O pós-moderno. Tradução: Ricardo Correia Barbosa. 4. ed. Rio de Janeiro: José Olympio, 1993.

MALINOWSKI, Bronislaw. Magic, Science and Religion and Other Essays. Illinois: The Free Press, 1948. Disponível em < http://monoskop.org/images/4/41/Malinowski_Bronislaw_Magic_Science_and_Religion_an d_Other_Essays_1948.pdf>. Acesso em 02 fev. 2016.

MARX, Karl. Contribuição à crítica da economia política. 2. ed. São Paulo: expressão popular, 2008.

MCINTOSH, Peggy. White privilege and male privilege: a personal account of coming to see correspondences through work in Women's Studies. 1988. (Working Paper 189). Center for Reserach on Women, Wellesley College.

NOGUEIRA, Marco Aurélio (Org.). Gramsci e a América Latina. Rio de Janeiro: Paz e Terra, 1988.

POLIAKOV, Léon. 0 mito ariano: ensaios sobre as fontes do racismo e dos nacionalismos. São Paulo: Perspectiva; Ed. Da Universidade de São Paulo, 1974.

SIMIONATO, Ivete. Gramsci: sua teoria, incidências no Brasil, influência no serviço social. Florianópolis: Ed. da UFSC; São Paulo: Cortez, 1995. 